This journal is the official publication of Bangladesh Society of Physiologists (BSP)

Web URL: www.banglajol.info/index.php/JBSP

Abstracted /indexed in Index Copernicus, Director of Open Access Journal, HINARI Index Medicus for South East Asia Region, Google Scholar, 12OR, infobse index, Open J gate, Cite factor, Scientific indexing services

pISSN-1983-1213; e-ISSN-2219-7508

\title{
Article
}

Article information:

Received: 3rd Aug 2021

Accepted: 5 th Nov 2021

DOI: https://doi.org/10.3329/jbsp.v16i2.57568

Corresponding author:

Mahfuja Begum Shumi, Resident, Department of Physiology, Bangabandhu Sheikh Mujib Medical University, Dhaka, Tele: 01736565909. Email-dr.mahfujashumi@ gmail.com

Cite this article:

Shumi MB, Begum S. Evaluation of iron status in metabolic syndrome. J Bngladesh Soc Physiol $2021 ; 16(2): 82-87$

This article is open access licensed under CC BY NC SA which allows readers copy, distribute, display, and perform the work and make derivative works based on it only for noncommercial purposes.

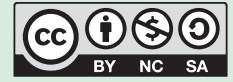

\section{Evaluation of iron status in metabolic syndrome}

\author{
Mahfuja Begum Shumi ${ }^{1}$, Shelina Begum ${ }^{1}$ \\ 1. Department of Physiology, Bangabandhu Sheikh Mujib Medical \\ University, Dhaka
}

\section{Abstract}

Background: Metabolic syndrome (MetS) is a cluster of interconnected risk factors that adversely affects all the organs of the body. Oxidative stress resulting from excess tissue iron causing insulin resistance, tissue damage and other complications are observed in MetS. Objectives: To assess iron status by serum iron, ferritin, total iron binding capacity (TIBC) and transferrin saturation (TS) levels in female MetS patients. Method: This cross sectional study was conducted in the Department of Physiology, Bangabandhu Sheikh Mujib Medical University (BSMMU), Shahbag, Dhaka from March, 2019 to February, 2020 on total thirty female MetS patients aged 25 to 45 years. Thirty (30) age matched apperantly healthy female subjects were enrolled as control. Serum iron, ferritin levels, TIBC and TS were measured by standard biochemical methods. Data were expressed as mean $\pm \mathrm{SD}$. Statistical analysis was done by Independent sample ' $t$ ' test. Results: In this study, mean serum ferritin was significantly higher $(\mathrm{p}<0.001)$ and mean serum TIBC was significantly lower $(\mathrm{p}<0.05)$ in patients than that of controls In addition, $43.3 \%$ of MetS patients had excess ferritin and $26.67 \%$ patients had low TIBC whereas no control subjects had abnormal ferritin or TIBC and the difference between MetS and control was statistically significant. Conclusion: From the results of this study it can be concluded that higher iron status may be associated with metabolic syndrome.

Key words: Metabolic syndrome, serum iron, serum ferritin, serum TIBC, transferrin saturation. 
Introduction

D iabetes and obesity are major threats to human health in the $21^{\text {st }}$ century. Along with them some other interrelated cardiovascular risk factors are prone to cluster in an individual giving rise to a condition known as MetS. ${ }^{1}$ According to International Diebetes Federation (IDF) definition, MetS is characterized by central obesity (waist circumference, $\geq 90 \mathrm{~cm}$ for men or $\geq 80 \mathrm{~cm}$ for women of South Asia) plus 2 or more of the following criteria $-(1) \mathrm{TG}-\geq 150 \mathrm{mg} / \mathrm{dl}$ (1.7 $\mathrm{mmol} / \mathrm{l}$ ) or specific treatment for this lipid abnormality, (2) HDL-C- $<40 \mathrm{mg} / \mathrm{dl}$ (1.03mmol/1) in men, $<50 \mathrm{mg} / \mathrm{dl}(1.29 \mathrm{mmol} / \mathrm{l})$ in women or specific treatment for this lipid abnormality, (3) systolic $\mathrm{BP} \geq 130$ or diastolic $\mathrm{BP} \geq 85 \mathrm{~mm} \mathrm{Hg}$ ) or treatment for previously diagnosed hypertension and (4) Fasting plasma glucose- $\geq 100 \mathrm{mg} / \mathrm{dl}$ (5.6 mmol/l) or previously diagnosed type 2 diabetes. ${ }^{1-2}$ Over last few decades, worldwide prevalence is about $20-25 \%$, whereas in Bangladesh, its overall prevalence is $30 \%$, in female $32 \%$, in male $25 \%{ }^{3}$

Iron in human body has a key role in oxygen transport and respiratory chain enzymes in mitochondria and the citric acid cycle via the capability to change its redox state. However, this characteristic also renders excess iron is detrimental for tissues-mostly via the formation of reactive oxygen species (ROS) by Fenton and Haber-Weiss reactions causing oxidative stress. ${ }^{4-6}$ This oxidative stress triggers inflammatory response and cellular injury that leads to cell damage and death. ${ }^{7}$

To meet up biological iron requirements and avoid systemic iron toxicity, iron stores are tightly equilibrated by a complex molecular network. ${ }^{4}$ Iron is stored as ferritin in many organs like liver, macrophage and spleen. ${ }^{8}$ Systemic iron homeostasis is maintained by hepcidin which inhibit iron export from the cell causing decreased in serum iron. ${ }^{4}$ Indicators of iron status include serum iron, serum ferritin, total iron-binding capacity and transferrin saturation. ${ }^{10}$ Previous studies suggested a positive association of indices of iron status and hyperferritinaemia with metabolic syndrome. ${ }^{8-10-12}$ Whereas Ryu et al. observed no relation between serum ferritin and metabolic syndrome. ${ }^{13}$ Hyperferritineimia with normal or mildly elevated transferrin saturation is common in this syndrome. ${ }^{14-15}$ On the other hand, Tavakoli-Hoseini et al. found elevated serum iron and ferritin but no significant relationship between TIBC and metabolic syndrome ${ }^{6}$. Whereas, some studies found normal level of iron in metabolic syndrome also. ${ }^{16}$

Because of conflicting results of different studies showing no clear cut evidence for the association of higher iron status in MetS this study has been designed to evaluate the iron status in MetS patients.

Methods

\section{Setting \& participants}

This cross sectional study was conducted in the Department of Physiology, Bangabandhu Sheikh Mujib Medical University (BSMMU), Shahbag, Dhaka from March, 2019 to February, 2020. The protocol of this study was approved by the Institutional Review Board of BSMMU. Thirty female subjects with MetS diagnosed according to IDF $^{2}$ aged 25-45 year were selected by purposive sampling from Department of Endocrinology, BSMMU and to compare with them, 30 apperantly healthy female subjects of similar age and sex were enrolled as control. All subjects studied at proliferative phase of their menstrual cycle to ignore hormonal effect. Subjects were motivated for voluntary participation and an informed written consent was taken.

\section{Exclusion criteria}

Subjects suffering from cardiovascular, respiratory, renal, thyroid disorders, liver disease, malignancy, acute or chronic inflammation, iron deficiency anemia and menstrual abnormality were excluded from this study. Moreover, women 
who are pregnant, history of blood transfusions or treatment with iron therapy within last 3 months, known case of hereditary haemochromatosis, recent history of surgery or illness, smokers, history of taking iron fortified contraceptives and post menopausal subjects were also excluded from the study.

\section{Data collection procedure}

Detail family, medical history was taken and thorough physical examination was done and recorded in a preformed data schedule. Blood pressure, waist circumference, height and weight were measured and BMI was calculated.

Under aseptic precaution venous blood was collected and sent to the Department of Biochemistry and and Molecular Biology for the estimation of fasting plasma glucose, lipid profile, SGPT and creatinine and serum iron, ferritin, TIBC and transferrin saturation and to the Department of Laboratory Medicine, BSMMU for the estimation of CBC. Based on biochemical report, final selection was done according to exclusion and inclusion criteria.
Statistical analysis

All data were expressed as mean \pm SD. Statistical analysis was done using SPSS version 16 . Independent sample ' $\mathrm{t}$ ' test and chi square test was done and $p$ value of $\leq 0.05$ was considered as statistically significant

\section{Results}

Baseline general characteristics of the subjects are shown in Table I. According to MetS definition, WC, SBP and DBP, fasting plasma glucose and serum TG were significantly higher $(\mathrm{p} \leq 0.001)$ and HDL-C was significantly lower ( $p$ $\leq 0.05$ ) in MetS group in comparison to control (Table I). The mean value of serum ferritin was significantly higher $(\mathrm{p} \leq 0.001)$ and TIBC was significantly lower $(\mathrm{p} \leq 0.05)$ in MetS group in comparison to control (Table II). On the other hand, serum iron and TS were not significantly different ( $p>0.05)$. Again 13(43.33\%) MetS patients had high serum ferritin and $8(26.67 \%)$ had low TIBC; whereas no control had higher serum ferritin and low serum TIBC respectively (Table III).

Table I: Age, WC, blood pressure, FBS, TG and HDL-C in two groups $(\mathrm{N}=60)$

\begin{tabular}{lccc}
\hline Parameters & MetS $(\mathrm{n}=30)$ & Control $(\mathrm{n}=30)$ & $\mathrm{p}$ value \\
\hline Age $($ years $)$ & $38.50 \pm 5.91$ & $36.10 \pm 5.29$ & 0.101 \\
& $(25.00-45.00)$ & $(26.00-45.00)$ & \\
WC $(\mathrm{cm})$ & $96.77 \pm 5.89$ & $74.97 \pm 5.05$ & $0.000^{* * *}$ \\
& $(85.00-113.00)$ & $(60.00-79.00)$ & \\
SBP $(\mathrm{mm}$ of Hg) & $134.50 \pm 12.27$ & $115.37 \pm 8.12$ & $0.000^{* * *}$ \\
& $(110.00-160.00)$ & $(100.00-125.00)$ & \\
FPG $(\mathrm{mmol} / \mathrm{l})$ & $9.02 \pm 3.49$ & $4.40 \pm 0.39$ & $<0.000^{* * *}$ \\
& $(5.00-16.00)$ & $(4.40-5.08)$ & $<0.000^{* * *}$ \\
TG $(\mathrm{mg} / \mathrm{dl})$ & $215.20 \pm 104.36$ & $99.90 \pm 32.00$ & \\
& $(94.00-466.00)$ & $(30.00-175.00)$ & $<0.024^{*}$ \\
HDL-C $(\mathrm{mg} / \mathrm{dl})$ & $39.00 \pm 7.47$ & $44.37 \pm 10.22$ & $(31.60-68.00)$ \\
& $(23.00-56.00)$ & & \\
\hline
\end{tabular}

Data were expressed as Mean \pm SD. Values in parentheses indicate ranges; Statistical analysis was done by Independent sample ' $t$ ' test; MetS- Metabolic syndrome patients; WC-Waist circumference; SBP-Systolic blood pressure; DBPDiastolic blood pressure; ${ }^{* * *} \mathrm{p} \leq 0.001$;FBS-Fasting blood sugar; TG-Triglyceride; HDL-C-High density lipoproteincholesterol; * $\mathrm{p} \leq 0.05 ; \mathrm{N}=$ Total number of subjects; $\mathrm{n}=$ number of subjects in each group. 
Table II: Serum iron, ferritin, TIBC, transferrin saturation in two groups $(\mathrm{N}=60)$

\begin{tabular}{lccc}
\hline Parameters & MetS $(\mathrm{n}=30)$ & Control $(\mathrm{n}=30)$ & $\mathrm{p}$ value \\
\hline Iron $(\mu \mathrm{g} / \mathrm{dL})$ & $48.03 \pm 20.89$ & $58.40 \pm 21.24$ & \\
& $(14.00-83.00)$ & $(15.00-95.00)$ & 0.062 \\
Ferritin $(\mathrm{ng} / \mathrm{mL})$ & $202.47 \pm 204.63$ & $44.73 \pm 24.23$ & $0.000^{* * *}$ \\
& $(8.20-545.00)$ & $(5.53-79.50)$ & \\
TIBC $(\mu \mathrm{g} / \mathrm{dL})$ & $292.80 \pm 129.02$ & $351.70 \pm 60.67$ & \\
& $(23.00-515.00)$ & $(249.00-500.00)$ & $0.027^{*}$ \\
TS $(\%)$ & $30.23 \pm 44.12$ & $17.64 \pm 7.95$ & 0.129 \\
& $(2.91-204.35)$ & $(3.06-32.07)$ & \\
\hline
\end{tabular}

Data were expressed as Mean \pm SD. Values in parentheses indicate ranges;Statistical analysis was done by Independent sample ' $t$ ' test; MetS - Subjects with metabolic syndrome; TIBC-Total iron binding capacity; TSTransferrin saturation; ${ }^{* * *} \mathrm{p} \leq 0.001 ;{ }^{*} \mathrm{p} \leq 0.05 ; \mathrm{N}=$ Total number of subjects; $\mathrm{n}=$ number of subjects in each group.

Table III: Frequency distribution of abnormal serum iron status in two groups $(\mathrm{N}=60)$

\begin{tabular}{lccc}
\hline Parameters & MetS $(\mathrm{n}=30)$ & Control(n=30) & p value \\
& No. $(\%)$ & No. $(\%)$ & \\
\hline Ferritin $(\mathrm{ng} / \mathrm{mL})$ & $13(43.33)$ & $0(0)$ & $0.000^{* * *}$ \\
TIBC $(\mu \mathrm{g} / \mathrm{dL})$ & $8(26.67)$ & $0(0)$ & $0.002^{*}$ \\
\hline
\end{tabular}

Data were expressed as Mean $\pm \mathrm{SD}$. Values in parentheses indicate ranges;Statistical analysis was done by Independent sample ' $t$ ' test; MetS- Subjects with metabolic syndrome; TIBC-Total iron binding capacity; TSTransferrin saturation; ${ }^{* * *} \mathrm{p} \leq 0.001 ;{ }^{*} \mathrm{p} \leq 0.05 ; \mathrm{N}=$ Total number of subjects; $\mathrm{n}=$ number of subjects in each group; Cut points:Ferritin- $>120$,TIBC- $<250^{22}$

\section{Discussion}

The present study was done to observe iron status in MetS. In our study, significantly higher serum ferritin as well as hyperferritineimia is notably observed in MetS patients. Similar results were reported by some previous studies. ${ }^{6,12,15}$ In addition, lower TIBC was in MetS could not be compared due to the unavailability of published data.

Literature review showed increased release of inflammatory cytokines (TNF- $\alpha$, IL-1, IL-6 \& leptin) in obese, stimulate excessive secretion of hepcidin from the pancreas, liver and adipose tissue. ${ }^{17}$ This hepcidin causes internalization and degradation of ferroportin which impairs iron

Volume 16 No. 2 December 2021: 82-87 export from the cell. ${ }^{18-19}$ Sequestration of iron leads to higher cellular and serum ferritin. Serum ferritin may be derived from ferritin-loaded macrophage in a non-classical secretory pathway ${ }^{17,20}$ or simply leak from hepatocyte or damaged cell. ${ }^{21}$

As there is enough iron stored within cell, it may inhibit the negative feedback effect of increasing TIBC in response to low serum iron. So TIBC remains low. ${ }^{22}$

TIBC is an indirect measure of transferrin. As transferrin is a negative acute phase reactant, so transferrin may also decrease due to obesity related low grade inflammation. ${ }^{23-24}$ Simultaneously, transferrin is a known anti-oxidant which 
binds with iron and keeps iron in an inactive state for redox reaction. As transferrin is decreased, iron becomes free and it catalyses the Fenton and Haber-Weiss reactions and generates hydroxyl radical. ${ }^{24,25}$ Also in hyperglycemia, glycation of transferrin occurs which impairs its iron binding capacity.

So, both decreased synthesis and impaired functioning of transferrin may be responsible for decreased TIBC in MetS. ${ }^{23}$ Thus non transferrin bound iron (NTBI) promotes reactive oxygen species production. Also, in case of insulin resistance, glycation of cell surface protein of red blood cell membrane occurs and may cause excessive red blood cells lysis. It also releases free iron. The oxidative reactions by radicals initiate and propagate lipid peroxidation and cause protein, lipid and DNA damage. ${ }^{8,23-24}$ In response to oxidative injury, it leads to inflammation in the major organs like heart, lung, liver and pancreas.

\section{Conclusion}

From the results of this study, it can be concluded that higher iron status is associated with metabolic syndrome.

Conflict of interest: Authors declare no conflict of interest.

\section{Acknowledgement}

The authors acknowledge the Department of Biochemistry and Molecular Biology and laboratory, BSMMU for their kind co-operation regarding their laboratory tests.

\section{References}

1. Alberti KG, Zimmet P, Shaw J. Metabolic syndrome - a new world wide definition. A consensus statement from the international diabetes federation. Diabet Med 2006;23(5):469-80.

2. Huang PL. A comprehensive definition for metabolic syndrome. journals biologists com 2009; 2(5-6):231-7.
3. Chowdhury MZ, Anik AM, Farhana Z, Bristi PD, Al Mamun BA, Uddin MJ, Fatema J, Akter T, Tani TA, Rahman M, Turin TC. Prevalence of metabolic syndrome in Bangladesh: a systematic review and meta-analysis of the studies. BMC public health 2018;18(1):308.

4. Datz C, Felder TK, Niederseer D, Aigner E. Iron homeostasis in the metabolic syndrome. Eur J Clin Invest 2013;43(2):215-24.

5. Das TK, Wati MR, Fatima-Shad K. Oxidative stress gated by Fenton and Haber Weiss reactions and its association with Alzheimer's disease. Arch Neurosci 2015;2(2).e60038

6. Tavakoli-Hoseini N, Ghayour-Mobarhan M, Parizadeh SM, Mirhafez SR, Tavallaie Sh FG. Relationship between indices of iron status and metabolic syndrome in an Iranian population. J Anal Res Clin Med 2014;2(4):197-205

7. Kim J, Wessling-Resnick M. The role of iron metabolism in lung inflammation and injury. J Allergy Ther 2012;3(Suppl 4).004 doi: 10.4172/ 2155-6121.

8. H Yoon, JS Go, KU Kim, KW Lee. The association of serum ferritin and metabolic syndrome and metabolic syndrome score in Korean adults. Korea science 2016;48(4):287-95.

9. Bozzini C, Girelli D, Olivieri O, Martinelli N, Bassi A, De Matteis G, Tenuti I, Lotto V, Friso S, Pizzolo F, Corrocher R. Prevalence of body iron excess in the metabolic syndrome. Diabetes. 2005; 28(8): 2061-3.

10. Ruhul A, Sharmin H, Luthfor A, Farzana S, Liaquat A. Ferritin and Soluble Transferrin Receptors in Type 2 Diabetic and Non-diabetic Post-menopausal Women in Dhaka, Bangladesh. Malays. J Nutr 2010 ;16(3).

11. Lee HJ, Jang HB, Park JE, Park KH, Kang JH, Park SI, Song J. Relationship between serum levels of body iron parameters and insulin resistance and metabolic syndrome in Korean children. Osong Public Health Res Perspect 2014 ;5(4):204-10.

12. Chang JS, Lin SM, Huang TC, Chao JC, Chen YC, Pan WH, Bai CH. Serum ferritin and risk of the metabolic syndrome: a population-based study. Asia Pac J Clin Nutr 2013;22(3):400.

13. Ryu SY, Kim KS, Park J, Kang MG, Han MA. Serum Ferritin and Risk of the Metabolic Syndrome in Some Korean Rural Residents. J Prev Med Public Health 2008;41(2):115-20.

Volume 16 No. 2 December 2021: 82-87 
14. Chen LY, Chang SD, Sreenivasan GM, Tsang PW, Broady RC, Li CH, Zypchen LN. Dysmetabolic hyperferritinemia is associated with normal transferrin saturation, mild hepatic iron overload, and elevated hepcidin. Ann Hematol 2011; 90(2):139-43.

15. Felipe A, Guadalupe E, Druso P, Carlos M, Pablo S, Oscar C, Luis V, Diego M, Jaime R, Inés U, Federico L. Serum ferritin is associated with metabolic syndrome and red meat consumption. Oxid Med Cell Longev 2015;2015.

16. Brudevold R, Hole T, Hammerstrøm J. Hyperferritinemia is associated with insulin resistance and fatty liver in patients without iron overload. PloS one 2008;3(10).

17. McCracken E, Monaghan M, Sreenivasan S. Pathophysiology of the metabolic syndrome. Clin Dermatol 2018;36(1):14-20.

18. Aigner E, Feldman A, Datz C. Obesity as an emerging risk factor for iron deficiency. Nutrients 2014;6(9):3587-600.

19. Neves J, Leitz D, Kraut S, Brandenberger C, Agrawal R, Weissmann N, Mühlfeld C, Mall MA, Altamura S, Muckenthaler MU. Disruption of the hepcidin/ ferroportin regulatory system causes pulmonary iron overload and restrictive lung disease. EBioMedicine 2017;20:230-9.
20. Fernández-Real JM, McClain D, Manco M. Mechanisms linking glucose homeostasis and iron metabolism toward the onset and progression of type 2 diabetes. Diabetes care 2015;38(11): 2169-76.

21. Kell DB, Pretorius E. Serum ferritin is an important inflammatory disease marker, as it is mainly a leakage product from damaged cells. Metallomics 2014;6(4):748-73.

22. Higgins T, Eckfeldt JH, Barton JC, Doumas BT (2012). Hemoglobin, iron and bilirubin. In: Burtis CA, Ashwood ER, Bruns DE, editors. Tietz textbook of clinical chemistry and molecular diagnostics. $5^{\text {th }}$ USA. Elsevier Saunders: . p. 9851030

23. Campenhout AV, Van Campenhout CM, Lagrou AR, Manuel-y-Keenoy B. Transferrin modifications and lipid peroxidation: implications in diabetes mellitus. Free Radic Res 2003;37(10):1069-77.

24. Ahmed MS, Jadhav AB, Hassan A, Meng QH. Acute phase reactants as novel predictors of cardiovascular disease. ISRN Inflamm 2012 2012.

25. Halliwell B, Gutteridge JM. Role of free radicals and catalytic metal ions in human disease: an overview. In: Methods in enzymology, Academic Press; 1990 Jan Vol. 186, pp. 1-85. 